\title{
Individual allergens as risk factors for bronchial responsiveness in young adults
}

\author{
Susan Chinn, Deborah Jarvis, Christina Luczynska, Peter Burney
}

\begin{abstract}
Background-Bronchial responsiveness is known to be related to atopy, but the relative contribution of sensitisation to individual allergens in the UK, or whether serum total IgE is an independent risk factor, is unknown.

Methods-A random sample of 1864 men and women aged 20-44 years, drawn from family health service registers in Cambridge, Ipswich and Norwich, was invited to answer a detailed questionnaire, undergo skin prick tests and methacholine bronchial challenge, and provide a serum sample for measurement of total and specific IgE. The relation of bronchial responsiveness to risk factors was studied in 749 subjects $(40.2 \%)$ with complete data.

Results-Bronchial responsiveness was increased in those sensitised to cat, $D$ pteronyssinus, Timothy grass and Cladosporium, but decreased in subjects also positive to birch allergen. Additional skin prick tests added little information. Serum total IgE was not significantly related after adjustment for specific IgE to the five allergens. Increasing titres of specific IgE to $D$ pteronyssinus were associated with increasing bronchial responsiveness. Specific IgE to Cladosporium had a prevalence of around $3 \%$, but was associated with greatly increased responsiveness. Decreased baseline lung function was related $(p<0.001)$ to increased responsiveness. There was an interaction between age and smoking status, with lower responsiveness in older non-smokers.

Conclusion-Atopy is the most important risk factor for bronchial responsiveness in this age group, but effects are not additive across all allergens. Research in reducing exposure to house dust mite should also address the role of Cladosporium sensitisation and exposure to indoor moulds.

(Thorax 1998;53:662-667)
\end{abstract}

Department of Public Health Medicine, UMDS Guy's Campus, London SE1 3QD, UK S Chinn

D Jarvis

C Luczynska

P Burney

Correspondence to: Miss S Chinn.

Received 22 December 1997 Returned to authors 2 March 1998

Revised manuscript received

17 April 1998

Accepted for publication

22 April 1998

Keywords: bronchial hyperresponsiveness; allergens; young adults

The identification of risk factors for bronchial hyperresponsiveness (BHR) is important in furthering the understanding of the causes of asthma and of chronic obstructive lung disease. Atopy has been recognised as a risk factor, as defined by skin prick tests ${ }^{1-3}$ or serum specific IgE, ${ }^{4}$ or both. ${ }^{56}$ Only one of these studies, ${ }^{6}$ in Spain, addressed the question of the relative importance of individual allergens in adults. Sunyer et al found that serum total IgE was associated with BHR independently of atopy, defined by specific IgE to at least one of five allergens, ${ }^{4}$ but this has not been studied in other populations or with analysis of individual allergens in adults. One recent study has included specific IgE in the $\mathrm{UK}^{5}$ but results were combined with skin prick tests and total IgE; no author has considered the relative merits of including skin prick tests or specific IgE as measures of atopy in an epidemiological study.

The effects of sensitisation to individual allergens, measured by either skin prick tests or by specific IgE, age, sex, smoking, baseline lung function, and a number of other possible factors were studied in data for subjects from the English arm of the European Community Respiratory Health Survey (ECRHS).

\section{Methods}

SAMPLING

The protocol for the ECRHS has been described in detail elsewhere. ${ }^{78}$ In stage I, in three centres in East Anglia, ${ }^{9}$ subjects aged 20-44 years selected at random from the family health services register were sent a short respiratory symptom questionnaire. A 20\% random sample of subjects was selected to take part in stage II. Those who had already responded to stage I were invited to answer a more detailed administered questionnaire, and to take part in blood tests, skin tests, assessment of lung function by spirometry, and airway challenge with methacholine.

METHACHOLINE CHALLENGE

Baseline forced expiratory volume in one second $\left(\mathrm{FEV}_{1}\right)$ and forced vital capacity (FVC) were measured in all subjects who agreed. Subjects were advised to avoid smoking for one hour and to avoid use of a $\beta_{2}$ agonist or anticholinergic inhaler for four hours or oral medication ( $\beta_{2}$ agonist, theophylline or antimuscarinic) for eight hours before the test. When possible, subjects who reported a respiratory tract infection in the previous three weeks were rescheduled.

Subjects were permitted nine attempts to provide at least two technically acceptable manoeuvres. All those whose $\mathrm{FEV}_{1}$ was at least $70 \%$ predicted, ${ }^{10}$ and more than 1.51 , were invited to undergo methacholine challenge unless they reported that they had heart disease, epilepsy, were pregnant or breastfeeding, or were taking a $\beta$ blocker.

Bronchial challenge commenced with inhalation of saline diluent, and the maximum post diluent $\mathrm{FEV}_{1}$ recorded two minutes later was used as the control value. Those whose control 
$\mathrm{FEV}_{1}$ was less than $90 \%$ of the baseline value were not challenged further. Mefar dosimeters were set to deliver methacholine over a one second period. Those who denied respiratory symptoms suggestive of asthma received methacholine starting at a cumulative dose of $0.0078 \mathrm{mg}$ and then in quadrupling doses (short schedule) until a fall in $\mathrm{FEV}_{1}$ of $10 \%$ from the control value was recorded, after which doubling doses were used. All other subjects had an initial dose of $0.00195 \mathrm{mg}$ and then received doubling doses (long schedule). Two minutes after each inhalation subjects had up to five attempts to achieve two technically satisfactory $\mathrm{FEV}_{1}$ manoeuvres. The test was stopped if there was a greater than $20 \%$ fall in $\mathrm{FEV}_{1}$ from the control value, the maximum cumulative dose of $1 \mathrm{mg}$ had been reached, the subject was not able to perform two technically satisfactory manoeuvres following any dose, or the subject did not wish to continue.

SKIN PRICK TESTS

Skin prick tests were conducted using Phazets (Pharmacia Diagnostics). The allergens used for skin testing were cat, Dermatophagoides pteronyssinus (house dust mite), Cladosporium herbarum, Alternaria alternata, Timothy grass, olive, birch, Parietaria judaica, and common ragweed. Histamine $(1 \mathrm{mg} / \mathrm{ml}$ histamine dihydrochloride) was used as a positive control and an uncoated Phazet as the negative control. Tests were performed on the volar surface of the forearm using a standard template and the wheal size was recorded at 15 minutes as the biggest diameter and the diameter at $90^{\circ}$ to its midpoint, each to the nearest whole millimetre. Mean wheal diameter was calculated as the average of the two diameters. Skin prick tests were regarded as positive if the mean wheal diameter was greater than zero, ${ }^{16}$ but the cut off points of $<3 \mathrm{~mm}$ and $<2 \mathrm{~mm}$ were also considered. Data for the few subjects with a negative control wheal greater than zero were omitted.

TOTAL AND SPECIFIC IGE

Serum total IgE and specific IgE to cat, $D$ pteronyssinus, Cladosporium, Timothy grass and birch were measured using the Pharmacia CAP System. The measurement range for total IgE was $2-2000 \mathrm{kU} / 1$ and $0.35-100 \mathrm{kU}_{\mathrm{A}} / 1$ for specific IgE. Specific IgE results were regarded as positive if $>0.35 \mathrm{kU}_{\mathrm{A}} / 1$. Total $\mathrm{IgE}$ was logarithmically transformed.

STATISTICAL ANALYSIS

As a new measure of dose response slope has been adopted for between centre analyses in the ECRHS, ${ }^{11}$ this is used as the main measure of BHR, but the dose producing a $20 \%$ fall in forced expiratory volume $\left(\mathrm{PD}_{20}\right)$ was also analysed in accordance with the recommendation of Rijcken and Schouten. ${ }^{12} \mathrm{PD}_{20}$ was estimated by fitting an exponential curve to decline in maximum $\mathrm{FEV}_{1}$ with log dose. ${ }^{13}$ Log slope, calculated by regressing the percentage fall in $\mathrm{FEV}_{1}$ on $\log _{10}$ (dose), ${ }^{11}$ required transformation in order to satisfy the assumptions of standard statistical analysis-that is, Normality and homogeneity of variance - the transformation
$100 /(\log$ slope +10$)$ was found to be appropriate. ${ }^{14}$ The term "slope" is used for transformed log slope as used in the ECRHS. ${ }^{15}$

Age was included as a continuous variable after its relation to bronchial responsiveness showed no significant departure from linearity. A smoker was defined as a subject who had smoked at least 20 packs of cigarettes or $12 \mathrm{oz}$ of tobacco in a lifetime, or at least one cigarette per day or one cigar a week for one year; smokers were divided into current and ex-smokers. For the analyses baseline $\mathrm{FEV}_{1}$ was expressed as the standardised difference from the internally derived predicted value based on age, height and sex in non-smokers, and as a percentage of FVC $\left(\mathrm{FEV}_{1} / \mathrm{FVC}\right)$. The date of testing was divided into four seasons. Subjects who were tested despite respiratory infection or recent medication were included in the analysis.

Other variables included as independent variables were the centre, social class (I, II, III non-manual, III manual, IV, V and unknown), cooking with gas or using an open gas fire, and current exposure to vapours, gas, dust or fumes at work, number of siblings and birth order, parental atopy, height, log body mass index, and passive smoking, estimated in hours per day by those giving a positive answer to "Have you been regularly exposed to tobacco smoke in the last 12 months?" Interactions of age with smoking and atopy, and of sex with age, atopy, $\mathrm{FEV}_{1} / \mathrm{FVC}$, cooking with gas or using an open gas fire were assessed.

As multiple regression analysis of a continuous variable has greater power to detect an association than a corresponding analysis with a binary variable, BHR was first analysed as slope using the variables as detailed above. Skin prick test results were used initially, but serum total IgE was included. Interactions not significant at the $10 \%$ level were removed, as were main effects considered as potential confounders but without strong a priori grounds for inclusion. The relations of slope to skin prick tests and specific IgE were then compared. $\mathrm{PD}_{20}$ was analysed using multiple logistic regression on the variables retained in the analysis of slope, a subject with $\mathrm{PD}_{20}<1 \mathrm{mg}$ being considered as responsive. The relation of BHR to individual wheal size was also investigated. Titres of specific IgE were considered in addition to the dichotomous classification.

\section{Results}

RESPONSE

Of the 1864 subjects selected at random to take part in stage II, 1198 responded to at least part of the study. Responders were more likely to be female than male, ${ }^{17}$ but of the responders women were less likely than men to provide data from the methacholine challenge (table 1). The 856 subjects with methacholine challenge data were more likely than those unable or unwilling to take part to have a parent with atopy, less likely to be a current smoker, had a higher mean $\mathrm{FEV}_{1} \%$ predicted, and a lower mean total IgE (table 2).

There was a slightly higher prevalence of atopy in those not providing methacholine 
Table 1 Response and selected characteristics of responders to stage II

\begin{tabular}{|c|c|c|}
\hline Selected & 1864 & \\
\hline Responded to stage II $(\%)^{1}$ & $1198(64.3)$ & \\
\hline Methacholine challenge $^{2}$ & Yes & $\mathrm{No}^{3}$ \\
\hline n (\%) & $856(71.5)$ & 342 \\
\hline Mean (SD) age & $33.5(6.8)$ & $33.1(7.0)$ \\
\hline Female $(\%$ of $n)$ & $449(52.5)$ & $235(68.7)$ \\
\hline Parental atopy (\% of $n)$ & $270(31.5)$ & $90(26.3)$ \\
\hline Non smokers ( $\%$ of $n)$ & $447(52.2)$ & $175(51.2)$ \\
\hline Ex smokers (\% of $n)$ & $186(21.7)$ & $65(19.0)$ \\
\hline Current smokers ( $\%$ of $n)$ & $220(25.7)$ & $102(29.8)$ \\
\hline Data available (n') & 856 & $168^{4}$ \\
\hline Recent RI (\% of n') & $30(3.5)$ & $6(3.6)$ \\
\hline Recent medication ( $\%$ of $n^{\prime}$ ) & $18(2.1)$ & $18(10.7)$ \\
\hline Mean (SD) $\mathrm{FEV}_{1}(\%$ pred) & $105.6(11.5)$ & $98.4(19.9)$ \\
\hline Mean (SD) $\mathrm{FEV}_{1} / \mathrm{FVC}$ & $82.9(6.2)$ & $81.1(10.1)$ \\
\hline
\end{tabular}

${ }^{1}$ Responded to at least the questions on smoking.

${ }^{2}$ Valid slope, therefore at least two doses of methacholine.

${ }^{3}$ Subjects who declined lung function or were ineligible for challenge or unable to proceed.

${ }^{4}$ Subjects who had baseline lung function but were ineligible for challenge, declined further participation, or were unable to proceed.

$\mathrm{RI}=$ respiratory infection $; \mathrm{FEV}_{1}=$ forced expiratory volume in one second $; \mathrm{FVC}=$ forced vital capacity.

Table 2 Response to skin prick tests and venepuncture, and resulting measures of atopy in responders to stage $I I^{i}$

\begin{tabular}{lll}
\hline Methacholine challenge $^{2}$ & Yes & No \\
$\mathrm{n}$ & 856 & 342 \\
With serum sample n' (\%) & $765(89.3)$ & $150(43.9)$ \\
GM total IgE & 27.2 & 38.2 \\
+ve serum specific IgE: & number $\left(\% \mathrm{n}^{\prime}\right)$ & \\
$\quad$ Cat & $68(8.9)$ & $31(20.7)$ \\
D pteronyssinus & $179(23.4)$ & $52(34.7)$ \\
Timothy grass & $185(24.2)$ & $81(27.3)$ \\
Cladosporium & $19(2.5)$ & $16(10.7)$ \\
Birch & $47(6.1)$ & \\
& & $192(56.1)$ \\
Skin tested n" (\%) & $846(98.8)$ & $37(19.3)$ \\
Skin prick test $>0$ mm: & number $\left(\% \mathrm{n}^{\prime \prime}\right)$ & $54(28.1)$ \\
Cat & $105(12.4)$ & $47(24.5)$ \\
D pteronyssinus & $233(27.5)$ & $6(3.1)$ \\
Timothy grass & $186(22.0)$ & $19(9.9)$ \\
Cladosporium & $30(3.6)$ & $19(9.9)$ \\
Birch & $45(5.3)$ & $8(4.2)$ \\
Alternaria & $67(7.9)$ & $4(2.1)$ \\
Olive & $31(3.7)$ & $7(3.6)$ \\
Parietaria & $8(1.0)$ & \\
Common ragweed & $12(1.4)$ & \\
\hline
\end{tabular}

${ }_{1,2}$ see footnotes to table 1 .

Table 3 Bronchial hyperresponsiveness as measured by $P D_{20}<1 \mathrm{mg}$ and slope in those sensitised and not sensitised to common allergens

\begin{tabular}{|c|c|c|c|c|}
\hline & $\begin{array}{l}P D_{20}<1 \mathrm{mg} \\
n(\%)\end{array}$ & & $\begin{array}{l}\text { Slope } \\
\text { mean (SD) }\end{array}$ & \\
\hline Total & $162(18.9)$ & & $7.23(2.10)$ & \\
\hline Sensitised & Yes & No & Yes & No \\
\hline \multicolumn{5}{|l|}{ Specific IgE to: } \\
\hline Cat & $37(54)$ & $109(16)$ & $5.63(2.12)$ & $7.38(2.00)$ \\
\hline D pteronyssinus & $69(39)$ & 77 (13) & $6.23(2.27)$ & $7.53(1.91)$ \\
\hline Timothy grass & $70(38)$ & $76(13)$ & $6.48(2.23)$ & $7.47(1.96)$ \\
\hline Cladosporium & $12(63)$ & $1.32(18)$ & $5.32(1.88)$ & $7.27(2.04)$ \\
\hline Birch & $14(30)$ & $1.32(18)$ & $6.78(2.13)$ & $7.26(2.07)$ \\
\hline \multicolumn{5}{|l|}{ Skin prick test $>0 \mathrm{~mm}$ : } \\
\hline Cat & $45(43)$ & $113(15)$ & $6.20(2.33)$ & $7.39(2.03)$ \\
\hline D pteronyssinus & $81(35)$ & $77(13)$ & $6.41(2.19)$ & $7.56(1.18)$ \\
\hline Timothy grass & $70(38)$ & $88(13)$ & $6.33(2.19)$ & $7.50(2.01)$ \\
\hline Cladosporium & $14(47)$ & $144(18)$ & $5.91(2.57)$ & $7.29(2.07)$ \\
\hline Birch & $15(33)$ & $143(18)$ & $6.94(2.12)$ & $7.26(2.10)$ \\
\hline Alternaria & $29(43)$ & $129(17)$ & $5.95(2.33)$ & $7.35(2.05)$ \\
\hline Olive & $9(29)$ & $149(18)$ & $7.31(2.19)$ & $7.24(2.10)$ \\
\hline Parietaria & $4(33)$ & $154(18)$ & $6.89(1.60)$ & $7.24(2.11)$ \\
\hline Common ragweed & $2(25)$ & $156(19)$ & $7.22(2.26)$ & $7.24(2.10)$ \\
\hline
\end{tabular}

challenge data than in those who did (table 2). About a quarter of subjects were sensitised to $D$ pteronyssinus or to Timothy grass by either measure of sensitisation. Positive skin prick tests to olive, Parietaria and common ragweed had a prevalence of less than $5 \%$ so these were combined in one variable with the other allergen not tested for specific IgE, Alternaria.
Table 3 shows the number and percentage of subjects with $\mathrm{PD}_{20}<1 \mathrm{mg}$ and mean (SD) of the slope according to sensitisation to each allergen. A lower slope is indicative of greater BHR. BHR was greater in those sensitised than in those not, for each allergen, defined by specific IgE or by skin prick test.

INITIAL ANALYSES

In the initial analyses the only significant interactions were between age and smoking status, and age and a positive skin prick test to cat. Main effects not significant at the $10 \%$ level were removed from the model. The relations of slope to total IgE and skin prick test results adjusted for the remaining variables are shown in table 4 . Higher values of total IgE were associated with greater responsiveness-that is, a lower slope. A positive skin prick test was associated with greater BHR, except for birch which, after adjustment for sensitisation to other allergens, was strongly associated with lower BHR, as shown by the greater mean slope. Redefining skin prick test results as positive when $<3 \mathrm{~mm}$ or $<2 \mathrm{~mm}$ led to very similar but less statistically significant results as the prevalence of a positive test was reduced.

Table 5 shows the results when the analysis was repeated using specific IgE in place of skin prick tests. Despite one variable less, the model explained a similar amount of the within centre variation in bronchial responsiveness $333.3 \%$ compared with $33.0 \%$ ). The relations were very similar, with the exception of total $\mathrm{IgE}$, which was fairly strongly associated with slope in the skin prick test model $(\mathrm{p}=0.003)$ but only weakly $(\mathrm{p}=0.12)$ in the specific $\operatorname{IgE}$ model, and sensitisation to Cladosporium which was not significantly associated with slope in the skin prick test model $(\mathrm{p}=0.18$ ) but was strongly associated when measured by specific $\operatorname{IgE}$. The interaction of age and specific $\operatorname{IgE}$ to cat was not statistically significant $(p=0.12)$.

An increase in BHR, as shown by a decrease in slope, was found with an increasing atopic response to $D$ pteronyssinus, whether as measured by a greater mean wheal diameter $(\mathrm{p}=$ $0.003)$ or a greater specific IgE titre $(p=0.02)$, but no association was observed with wheal diameter or specific IgE titre for the other allergens $(p>0.2)$.

FINAL ANALYSIS

The final model, omitting the interaction between age and specific IgE to cat but including the specific IgE titre for $D$ pteronyssinus, is shown in table 6 . The difference in mean slope between those positive and negative for cat was similar to that for Timothy grass. Those positive to Cladosporium had responsiveness increased by considerably more than those positive to cat or Timothy grass, and by an amount only exceeded by those with higher titres to $D$ pteronyssinus. Greater baseline lung function and height and being male were associated with lower BHR. There were differences between the centres not explained by the other factors in the model, those tested in Cambridge being more responsive than those in Ipswich or Norwich. Parental atopy was only weakly 
Table 4 Relation of slope to total IgE and positive skin prick tests, adjusted for each other and centre, sex, baseline lung function, height, parental atopy, number of siblings, season of testing, and age/smoking interaction

\begin{tabular}{lllc}
\hline & $\begin{array}{l}\text { Mean } \\
\text { difference } \\
\text { from } \\
\text { negative test } \\
\text { or regression } \\
\text { coefficient }\end{array}$ & $\begin{array}{l}95 \% \\
\text { confidence } \\
\text { interval }\end{array}$ & p value \\
\hline Total IgE $\left(\log _{10} \mathrm{kU} / \mathrm{l}\right)$ & -0.31 & -0.52 to -0.11 & 0.003 \\
Positive skin prick test to: & -0.77 & -1.09 to -0.45 & $<0.001$ \\
$\quad$ pteronyssinus & -0.64 & -1.00 to -0.28 & $<0.001$ \\
Timothy grass & -0.47 & -1.16 to 0.22 & 0.18 \\
Cladosporium & 1.05 & 0.47 to 1.63 & $<0.001$ \\
Birch & -0.43 & -0.88 to 0.03 & 0.07 \\
Any of Alternaria, olive, Parietaria, common ragweed & -1.12 & -1.94 to -0.29 & 0.008 \\
Cat (at age 20) & 0.08 & 0.02 to 0.14 & 0.008 \\
Additional increase per year of age in cat sensitised & & & \\
$\quad$ subjects & & & \\
\hline
\end{tabular}

Number of subjects $=749$. Total within centre variation explained $33.0 \%$.

Table 5 Relation of slope to serum total and specific IgE, adjusted for each other and centre, sex, baseline lung function, height, parental atopy, number of siblings, season of testing, and age/smoking interaction

\begin{tabular}{lllc}
\hline & $\begin{array}{l}\text { Mean } \\
\text { difference from } \\
\text { negative test or } \\
\text { regression } \\
\text { coefficient }\end{array}$ & $\begin{array}{l}\text { 95\% } \\
\text { confidence } \\
\text { interval }\end{array}$ & p value \\
\hline Total IgE $\left(\log _{10} \mathrm{kU} / \mathrm{l}\right)$ & -0.17 & -0.37 to 0.04 & 0.12 \\
Specific IgE to: & -0.92 & -1.26 to -0.58 & $<0.001$ \\
D pteronyssinus & -0.50 & -0.85 to -0.15 & 0.005 \\
Timothy grass & -1.40 & -2.14 to -0.47 & $<0.001$ \\
Cladosporium & 0.66 & 0.09 to 1.23 & 0.02 \\
Birch & -1.33 & -2.24 to -0.42 & 0.004 \\
Cat (at age 20$)$ & 0.06 & -0.01 to 0.12 & 0.12 \\
Additional increase per year of age in cat & & & \\
$\quad$ sensitised subjects & & & \\
\hline
\end{tabular}

Number of subjects $=749$. Total within centre variation explained $33.3 \%$

Table 6 Final multiple regression model of relation of slope to specific IgE and other factors for 757 subjects

\begin{tabular}{|c|c|c|c|}
\hline Factor & $\begin{array}{l}\text { Mean difference } \\
\text { from reference group } \\
\text { or regression } \\
\text { coefficient }\end{array}$ & $\begin{array}{l}95 \% \text { confidence } \\
\text { interval }\end{array}$ & $p$ value \\
\hline Total IgE $\left(\log _{10} \mathrm{kU} / \mathrm{l}\right)$ & -0.13 & -0.34 to 0.08 & 0.23 \\
\hline \multicolumn{4}{|l|}{ Specific IgE to: } \\
\hline Cat & -0.59 & -1.09 to -0.08 & 0.02 \\
\hline D pteronyssinus (just positive) & -0.72 & -1.07 to -0.37 & $<0.001$ \\
\hline per $10 \mathrm{kU} / 1$ increase above 0.35 & -0.22 & -0.39 to -0.05 & 0.01 \\
\hline Timothy grass & -0.50 & -0.84 to -0.15 & 0.005 \\
\hline Cladosporium & -1.44 & -2.24 to -0.64 & $<0.001$ \\
\hline Birch & 0.49 & -0.08 to 1.06 & 0.09 \\
\hline$\left(\mathrm{FEV}_{1}\right.$ - predicted $) / \mathrm{RSD}$ & 0.37 & 0.21 to 0.53 & $<0.001$ \\
\hline $\mathrm{FEV}_{1} \% \mathrm{FVC}$ & 0.09 & 0.07 to 0.12 & $<0.001$ \\
\hline Per $10 \mathrm{~cm}$ of height & 0.36 & 0.16 to 0.55 & $<0.001$ \\
\hline Females - males & -0.75 & -1.12 to -0.38 & $<0.001$ \\
\hline \multicolumn{3}{|l|}{ Centre: } & $<0.001$ \\
\hline Ipswich-Cambridge & 0.55 & 0.20 to 0.89 & \\
\hline Norwich-Cambridge & 1.11 & 0.76 to 1.46 & \\
\hline Parental atopy & -0.23 & -0.50 to 0.04 & 0.10 \\
\hline \multicolumn{3}{|l|}{ Season of testing: } & 0.04 \\
\hline Spring-winter & 0.31 & -0.08 to 0.69 & \\
\hline Summer-winter & 0.02 & -0.35 to 0.39 & \\
\hline Autumn-winter & -0.22 & -0.68 to 0.23 & \\
\hline \multicolumn{3}{|l|}{ Number of siblings } & 0.08 \\
\hline 1 - none & 0.09 & -0.39 to 0.57 & \\
\hline 2 - none & 0.44 & -0.04 to 0.92 & \\
\hline 3 - none & 0.13 & -0.40 to 0.66 & \\
\hline 4 - none & 0.47 & -0.06 to 0.99 & \\
\hline \multicolumn{4}{|l|}{ Smoking: difference at age 20 from } \\
\hline \multicolumn{4}{|l|}{ Non-smoker } \\
\hline Ex-smoker & 0.54 & -0.24 to 1.32 & 0.18 \\
\hline Current smoker & 0.74 & 0.08 to 1.40 & 0.03 \\
\hline \multicolumn{4}{|l|}{$\begin{array}{l}\text { Age/smoking: increase per } 10 \text { years of } \\
\text { age in }\end{array}$} \\
\hline Non-smokers & 0.53 & 0.27 to 0.80 & $<0.001$ \\
\hline Ex-smokers & 0.10 & -0.31 to 0.51 & 0.64 \\
\hline Smokers & -0.16 & -0.54 to 0.21 & 0.39 \\
\hline
\end{tabular}

Total variation explained after adjusting for centre $33.3 \%$

$\mathrm{RSD}=$ residual standard deviation in prediction model for $\mathrm{FEV}_{1}$. associated with increased responsiveness $(\mathrm{p}=$ 0.10 ) after allowing for the subject's atopic status. Season of testing and number of siblings showed weak associations, those with siblings being less responsive than those with none, but no consistent trend was found. BHR was lower in older non-smokers, but no association was observed with age in smokers $(\mathrm{p}=0.006)$; smokers aged 20 were estimated to have less BHR than non-smokers of the same age.

Table 7 shows the corresponding multiple logistic regression. An odds ratio greater than one denotes a relation in the same direction as a negative coefficient in table 6 , and there is agreement between the two models in this respect. Sensitisation to birch was more strongly related to lower BHR, but the other allergens were less statistically significant in the logistic regression model, and D pteronyssinus titre was no longer statistically significant ( $\mathrm{p}=$ 0.22 ); the weakening of these relations may explain the sightly increased significance of parental atopy and number of siblings.

\section{Discussion}

This is the first report of the relative importance of sensitisation to individual allergens for BHR in the UK. There were strong associations of sensitisation to $D$ pteronyssinus and Timothy grass in terms of prevalence of sensitisation (table 2) and size of effect (tables 6 and 7). Sensitisation to Cladosporium, although relatively uncommon, was associated with a large increase in BHR, exceeded only by those with a large titre for specific IgE to $D$ pteronyssinus. Degree of sensitisation to $D$ pteronyssinus, as measured by titre, was related to BHR. The power to detect a relation to Cladosporium titre was low, so that a relation cannot be ruled out. In contrast there seemed little relation of BHR to degree of sensitisation to cat or Timothy grass, and sensitisation to cat was overall of less importance than that to $D$ pteronyssinus, Timothy grass or Cladosporium due to the combination of prevalence and size of effect. The decreased BHR in subjects sensitised to birch was unexpected, but was seen once sensitisation to any other single allergen was taken into account.

Other authors who have included both specific IgE and skin prick tests have combined the data, regarding positive to either as evidence of atopy. ${ }^{56}$ This tacitly assumes that all error is on the side of false negatives. However, as cut off points are arbitrary, for epidemiological purposes at least, this is unwarranted, and it is inconvenient and expensive to include both sets of measurements. In favour of skin prick tests are the fact that more subjects consent to their being performed than consent to venepuncture, at least in England, and that a larger number of allergens can be tested at lower cost. In favour of specific IgE are the difficulties in standardising methodology for skin prick tests, resulting in field worker variation. ${ }^{16}$

A wheal diameter greater than zero was regarded as positive, primarily because of the finding that this reduced field worker variation, but also so that the comparison with specific 
Table 7 Multiple logistic regression model for relation of $P D_{20} \leqslant 1 \mathrm{mg}$ to specific IgE and other factors for 757 subjects

\begin{tabular}{|c|c|c|c|}
\hline Factor & Odds ratio & $\begin{array}{l}95 \% \text { confidence } \\
\text { interval }\end{array}$ & $p$ value \\
\hline Total IgE $\left(\log _{10} \mathrm{kU} / \mathrm{l}\right)$ & 1.34 & 0.90 to 1.99 & 0.16 \\
\hline \multicolumn{4}{|l|}{ Specific IgE to: } \\
\hline Cat & 2.71 & 1.22 to 6.06 & 0.02 \\
\hline D pteronyssinus (just positive) & 2.16 & 1.20 to 3.89 & 0.01 \\
\hline per $10 \mathrm{kU} / 1$ increase above 0.35 & 1.18 & 0.90 to 1.55 & 0.22 \\
\hline Timothy grass & 3.21 & 1.84 to 5.57 & $<0.001$ \\
\hline Cladosporium & 8.79 & 2.43 to 31.77 & 0.001 \\
\hline Birch & 0.26 & 0.09 to 0.74 & 0.01 \\
\hline$\left(\mathrm{FEV}_{1}\right.$ - predicted $) / \mathrm{RSD}$ & 0.53 & 0.39 to 0.72 & $<0.001$ \\
\hline $\mathrm{FEV}_{1} \% \mathrm{FVC}$ & 0.90 & 0.86 to 0.94 & $<0.001$ \\
\hline Per $10 \mathrm{~cm}$ of height & 0.52 & 0.36 to 0.75 & 0.001 \\
\hline Females - males & 1.53 & 0.77 to 3.05 & 0.22 \\
\hline Centre: & & & 0.003 \\
\hline Ipswich-Cambridge & 0.42 & 0.23 to 0.76 & \\
\hline Norwich-Cambridge & 0.40 & 0.22 to 0.71 & \\
\hline Parental atopy & 1.76 & 1.10 to 2.82 & 0.02 \\
\hline Season of testing: & & & 0.60 \\
\hline Spring-winter & 0.72 & 0.35 to 1.47 & \\
\hline Summer-winter & 0.84 & 0.42 to 1.65 & \\
\hline Autumn-winter & 1.13 & 0.50 to 2.54 & \\
\hline Number of siblings & & & 0.02 \\
\hline 1 - none & 0.48 & 0.23 to 1.02 & \\
\hline 2 - none & 0.29 & 0.13 to 0.65 & \\
\hline 3 - none & 0.44 & 0.19 to 1.06 & \\
\hline 4 - none & 0.25 & 0.10 to 0.61 & \\
\hline \multicolumn{4}{|c|}{ Smoking: difference at age 20 from non-smoker } \\
\hline Ex-smoker & 0.94 & 0.20 to 4.39 & 0.94 \\
\hline Current smoker & 0.36 & 0.11 to 1.16 & 0.09 \\
\hline \multicolumn{4}{|l|}{ Age/smoking: per 10 years of age in } \\
\hline Non-smokers & 0.47 & 0.23 to 0.78 & 0.003 \\
\hline Ex-smokers & 0.54 & 0.23 to 1.26 & 0.16 \\
\hline Smokers & 1.20 & 0.63 to 2.26 & 0.58 \\
\hline
\end{tabular}

$\mathrm{RSD}=$ residual standard deviation in prediction model for $\mathrm{FEV}_{1}$.

$\mathrm{IgE}$ was not affected by large differences in the prevalence of sensitisation, and so that the relation to wheal diameter was calculated across the whole range of diameters. Despite the fairly similar prevalences (table 2), the agreement between a positive specific IgE and a positive skin prick test was not high; kappa ranged from 0.23 for Cladosporium to 0.73 for Timothy grass.

Our finding here that serum total $\operatorname{IgE}$ is related to BHR after adjustment for skin prick tests, but not after adjustment for specific IgE to five allergens, also militates against using skin prick tests. Sunyer et al found serum total IgE to be related after adjustment for a number of factors including atopy, as defined by specific IgE, ${ }^{4}$ but did not separate the individual allergens so underadjustment may have occurred. In our analysis total IgE was statistically significant $(p=0.04)$ if the individual allergens were replaced by the number of allergens to which the subject had specific IgE, with no allowance for degree of sensitisation. Significantly less variation in BHR $(p=0.001)$ was explained by the number of positive specific IgE results than when the five allergens were included as separate variables.

Baseline $\mathrm{FEV}_{1}$, both as a standardised difference from a predicted value based on height, age and sex and as percentage of FVC, was strongly related to BHR. Similar results were obtained for baseline $\mathrm{FEV}_{1}$, total and specific IgE, regardless of how $\mathrm{FEV}_{1}$ was analysed, whether as percentage predicted or whether published equations were used. ${ }^{10}$ However, the relations observed for height and sex are dependent on which baseline lung function measure is used, and extreme caution is required in drawing any conclusion. ${ }^{18}$ Parental atopy, season of testing, and number of siblings were only weakly associated with BHR after adjustment for the atopic status of the subject. Differences between centres were not explained by the factors considered, as found also by Sunyer $e t a l .{ }^{4}$

Lower BHR in older non-smokers, resulting in current smokers being more responsive than a non-smoker by the age of 30 , is compatible with other studies. ${ }^{15}$ No significant interaction in the association with age was found with sensitisation to individual allergens. Devereux et $a l,{ }^{3}$ following the ECRHS protocol, also found no interaction between age and atopic status in men. Possible explanations include lack of power to detect interactions of individual allergens over the limited age range, that the cross sectional relation found by Burney et al ${ }^{1}$ in data collected in 1984 was a cohort effect that is now less evident, or lack of adjustment for baseline lung function and individual allergens in that analysis.

Sunyer et al reported differences in the effect of smoking on BHR in atopic and non-atopic individuals, ${ }^{4}$ although the interaction term did not reach the conventional level of statistical significance. In the English data there was no evidence that smoking modified the effect of sensitisation on BHR. The relation of specific IgE to smoking differs between allergens, ${ }^{19}$ so again the use of a single term for atopy can be questioned.

BHR was analysed in two ways, as slope and by dichotomising $\mathrm{PD}_{20}$, with results that were largely in agreement. The absolute values of attributable risk for BHR, as calculated by Soriano et $a l,{ }^{6}$ are dependent on the dose used to dichotomise $\mathrm{PD}_{20}$, but their relative values show that sensitisation to $D$ pteronyssinus and Timothy grass are important determinants of bronchial responsiveness in Spain, and also that to olive. On examining the four allergens combined in the analysis for table 4 no relation was found in the English data to sensitisation to olive, Parietaria or ragweed, but BHR was increased in those sensitised to Alternaria, the most prevalent of the four. Using skin prick tests Peat et al showed that BHR was strongly related to degree of house dust mite sensitisation in Australian children, ${ }^{20}$ but that after mutual adjustment ryegrass and cockroach were of lesser importance and cat and Alternaria were of no importance. In contrast, in New Zealand children Sears et al showed house dust mite followed by cat fur and dog fur to be the most important, ${ }^{21}$ with no effect demonstrated for ryegrass pollen.

One advantage of using $\mathrm{PD}_{20}$ as a binary outcome is that the effect of omitting those unable to be tested or complete methacholine challenge can be investigated. Including 115 subjects with $\mathrm{PD}_{20}$ missing but having other data, and assuming the extreme case that $\mathrm{PD}_{20}$ $<1 \mathrm{mg}$ for each of these subjects, the results were similar to those in table 7. Censored regression of $\mathrm{PD}_{20}$, assuming a log-normal distribution, ${ }^{13}$ also gave similar results in qualitative terms. However, multiple regression analysis of slope has fewer assumptions than censored regression, and more power than 
logistic regression of $\mathrm{PD}_{20}$, which largely accounts for the differences in significance levels between the results in tables 6 and 7 .

Serum total $\mathrm{IgE}$ was not associated after adjustment for specific IgE to common allergens. The importance of analysing data using the individual allergens was shown by the negative relation of BHR to birch and the relation to degree of sensitisation only for house dust mite. In the UK the inclusion of skin prick tests as well as specific IgE adds little information in an epidemiological study. This study has identified sensitisation to house dust mite and Cladosporium as the most important risk factors for BHR in the UK but comparison with other studies suggests extreme caution in extrapolating findings to other populations. Only randomised controlled trials of exposure reduction can determine whether the relations are causal, but a reduction in humidity in the home may be beneficial in preventing exposure to Cladosporium as well as to house dust mite.

1 Burney PGJ, Britton JR, Chinn S, et al. Descriptive epidemiology of bronchial reactivity in an adult population: results from a community study. Thorax 1987;42:38-44.

2 Trigg CJ, Bennett JB, Tooley M, et al. A general practice based survey of bronchial hyperresponsiveness and its relation to symptoms, sex, age, atopy, and smoking. Thorax 1990;45:866-72.

3 Devereux G, Ayatollahi T, Ward R, et al. Asthma, airways responsiveness and air pollution in two contrasting districts responsiveness and air pollution in two contrasting

4 Sunyer J, Anto JM, Kogevinas M, et al. Smoking and bronchial responsiveness in non-atopic and atopic young adults. chial responsiveness in $n$

5 Ross S, Godden DJ, Abdalla M, et al. Outcome of wheeze in childhood: the influence of atopy. Eur Respir $\mathcal{F} 1995 ; 8$ 2081-7.
6 Soriano JB, Tobias A, Kogevinas M, et al. Atopy and non-specific bronchial responsiveness. A population-based assessment. Am f Respir Crit Care Med 1996;154:1636-40.
7 Burney PGJ, Luczynska C, Chinn S, et al. The European Community Respiratory Health survey. Eur Respir $\mathcal{F} 1994$; 7:954-60.

8 United Medical and Dental Schools of Guy's and St Thomas's Hospitals, Department of Public Health Medicine. Protocol for The European

9 Jarvis D, Lai E, Luczynska C, et al. The prevalence of Jarvis D, Lai E, Luczynska C, et al. The prevalence of
asthma and asthma-like symptoms in young adults in three East Anglian towns. Br f Gen Pract 1994;44:493-7.

10 Quanjer PhH, Tammeling, Cotes JE, et al. Lung volumes and forced ventilatory flows. Eur Respir $\mathcal{F}$ 1993; 6(Suppl 16):5-40.

11 Chinn S, Arossa WA, Jarvis DL, et al. Variation in nebuliser aerosol output and weight output from the Mefar dosimeter: implications for multi-centre studies. Eur Respir f 1997; 10:452-6.

12 Rijcken B, Schouten JP. Measuring bronchial responsiveness in epidemiology. Eur Respir f 1993;6:617-8.

13 Chinn S, Britton JR, Burney PGJ, et al. Estimation and Chinn S, Britton JR, Burney PGJ, et al. Estimation and repeatability of the response to inhaled
munity survey. Thorax 1987;42:45-52.

14 Chinn S. Choosing a transformation. F Appl Stat 1996;23: 395-404.

15 Chinn S, Burney P, Jarvis D, et al. Variation in bronchial responsiveness in the European Community Respiratory Health Survey (ECRHS). Eur Respir f 1997;10:2495-501.

16 Chinn S, Jarvis D, Luczynska CM, et al. Measuring atopy in a multi-centre epidemiological study. Eur F Epidemiol 1996; 12:155-62.

17 Jarvis D, Chinn S, Luczynska C, et al. Association of respiratory symptoms and lung function in young adults with use of domestic gas appliances. Lancet 1996;347:426-31.

18 Kronmal RA. Spurious correlation and the fallacy of the ratio standard revisited. F $R$ Statist Soc 1993;156:379-92.

19 Jarvis D, Luczynska C, Chinn S, et al. The association of age, gender and smoking with total IgE and specific IgE. Clin Exp Allergy 1995;25:1083-91.

20 Peat JK, Tovey E, Gray EJ, et al. Asthma severity and morbidity in a population sample of Sydney schoolchildren: Part II - Importance of house dust mite allergens. Aust NZ Part II - Importance of $1994 ; 24: 270-6$.

21 Sears MR, Herbison GP, Holdaway MD, et al. The relative risks of sensitivity to grass pollen house dust mite and cat dander in the development of childhood asthma. Clin Exp Allergy 1989;19:419-424. 